\title{
When is a choice not a choice? "Sham offers" and the asymmetry of adolescent consent and refusal
}

With adult clinical treatment there is a symmetry between consent and refusal: if she consents, the intervention is rendered permissible; if she refuses-or if she simply does not consent-the action is not permissible and is not performed. In some jurisdictions, for at least for a small set of cases (e.g., those involving certain forms of life-saving treatment), adolescent consent is not like this: it exhibits a distinctive asymmetry of consent and refusal. For such interventions, on the consent side of things the adolescent has the same power as an adult; however, if she refuses to consent to treatment other parties (e.g., courts) may authorise the intervention; the intervention is performed in spite of her refusal. Whilst her consent is always normatively efficacious the normative situation after refusal may be as it would be were she to have consented: the treatment is permitted, albeit by some other party.

One explanation of this asymmetry is that it is the result of a different, underlying, asymmetry in competence. A person might be at a level of competence sufficient to consent to an intervention but not at a level of competence to refuse it. The "bar" is higher, as it were, for refusal than consent and the adolescent might reach the lower "bar" but not the higher. In 'Transitional Paternalism: How Shared Normative Powers Give Rise to the Asymmetry of Adolescent Consent and Refusal' (2015) I developed an explanation and defence of the asymmetry of adolescent consent and refusal that does not rest upon or 
depend upon an appeal to the asymmetry of competence. ${ }^{1}$ I noted that asymmetries between consent and refusal are not restricted to adolescence, nor are they essentially tied to considerations of competence. Such asymmetries can (and do) arise when normative powers are shared. In some instances there may be good reason for two parties to each have the power to permit (or authorise) some agent to do $\mathrm{X}$ whilst neither party has the power to veto or block the other's permission (or authorisation).

One everyday example is that of a (certain kind of) shared bank account where both $A$ and $B$ have the power to authorise the bank to make a payment from the account, but neither has veto power. ${ }^{2}$ If either $A$ or $B$ decides to authorise the payment, their "consent" is normatively efficacious. However, if A decides to authorise a payment, but B decides not to, B's decision is normatively inert. Or, if B refuses to authorise a payment, A may authorise it anyway. Here, then, we have an asymmetry between consent and refusal, and it is nothing to do with A or B's competence. As I noted in 'Transitional Paternalism' there are (obviously) important differences between a shared bank account and the normative situation of adolescent consent to clinical interventions. ${ }^{3}$ More specifically what justifies-or "grounds"-the sharing of such powers will be different. The sharing of powers in the bank account case may be grounded in some kind of agreement or mutual consent. In contrast,

\footnotetext{
${ }^{1}$ N. Manson. Transitional Paternalism: How Shared Normative Powers Give Rise to the Asymmetry of Adolescent Consent and Refusal. Bioethics 2014; 29(2): 66-73. References to this paper will be in the form (TP, p.**).

${ }^{2}$ The claim is not that all, most or, indeed, any shared bank accounts need be structured in this way, all that the example is meant to show is that such an arrangement (individual power to authorise, without veto power) is coherent and to give us a sense of why it can be coherent.

${ }^{3}$ It is not a direct problem for the bank account analogy that the grounding for sharing normative powers differs from that of the grounding of sharing normative powers in the case of who authorises adolescent treatment. It is not the grounding (in contract, or in considerations of best interests) that gives rise to the asymmetry, it is the structure of the normative situation, the fact that normative powers are shared in a particular way (see footnote 6, p.354). In order to object to the theory one would have to do more than simply point out that the asymmetry of adolescent consent does not have the same justification as that of a shared bank account.
} 
in the adolescent case the sharing of powers is not justified by some prior contract. The grounding for such sharing of powers comes from elsewhere. I argued that it can be found in a theory of transitional paternalism: roughly, the idea that whilst the adolescent acquires new powers to permit her own treatment, there are good reasons to retain a residual bestinterests framework as a "backstop" such that other parties retain a limited power to authorise certain clinical interventions even in face of the adolescents' refusal.

Rob Lawlor argues that this account of the asymmetry of adolescent consent and refusal is seriously flawed. ${ }^{4}$ Lawlor offers four objections. Two of them can be dealt with quickly, whilst the third objection-the "sham choice" or "sham offer" objection-is much more challenging and as such will be the main focus of attention here. We shall then turn, briefly, to his fourth objection, one that rests upon an additional misunderstanding about the nature of consent. In explaining why such objections fail we secure a clearer-and tidierunderstanding of exactly what is going on in the asymmetry of adolescent consent and refusal. In addition, we gain a better understanding of why the asymmetry seems to be counter-intuitive or problematic when it is not.

\section{Misreading 1: transitional paternalism is all about Harris and the symmetry of competence}

Lawlor gives a great deal of prominence to a quotation from John Harris (for example, his abstract begins with the words "John Harris"). Lawlor dedicates a whole section "Manson's response to Harris" (p. 354). Lawlor's avowed aim is that of showing that 'Manson is mistaken if he thinks that his view conflicts with the Harris claim quoted early in the article' (p. 354). The quotation in question is: 'The idea that a child (or anyone) might competently

\footnotetext{
${ }^{4}$ R. Lawlor. Ambiguities and Asymmetries in Consent and Refusal: Reply to Manson Bioethics 2016; 30(5): 353357. References to Lawlor's paper will simply give the page number in the body text.
} 
consent to a treatment but not be competent to refuse it is palpable nonsense'. ${ }^{5}$ Lawlor seems to think that the aim in 'Transitional Paternalism' was somehow to show that John Harris is wrong about the symmetry of competence. The paper then (unwittingly) fails in its aim because it ends up agreeing with Harris that competence is symmetrical. This is a misleadingly selective focus on Harris. In the original article the Harris quotation is merely one of five including-importantly for the charge the Lawlor levies-two quotations that do not mention competence at all: 'It seems obvious that a right to give consent must also mean the right to refuse consent' ${ }^{6}$; It seems obvious that the power to give consent must also mean the power to withhold consent'. ${ }^{7}$ If the sole or primary target really were something to do with competence, these would be odd quotations to put to the fore. ${ }^{8}$

The main (and explicitly stated) aim of 'Transitional Paternalism' was to move beyond a discussion of the asymmetry of consent and refusal in terms of the symmetry (or otherwise) of decisional competence. The structure of 'Transitional Paternalism' makes this clear. It opens with a puzzle about the asymmetry of consent and refusal, with a (non-exhaustive) range of illustrative quotations, including some that say something like "insofar as competence is symmetrical, the asymmetry between consent and refusal is absurd". It then goes on to explore an explanation of the asymmetry in terms of an asymmetry of competence. The discussion of the symmetry of competence is part of a preamble to offering a novel, better, account of the asymmetry, one that goes beyond a focus on

\footnotetext{
5 J. Harris. Consent and end of life decisions. J Med Ethics 2003;29:10-15.

${ }^{6}$ J.A. Devereux, D.P.H Jones \& D.L, Dickenson. Can children withhold consent to treatment? $\mathrm{Br}$ Med J 1993;306:1459-61 (p. 1460).

${ }^{7}$ D. Dickenson. Children's informed consent to treatment: is the law an ass? J Med Ethics 1994; 20: 205.

${ }^{8}$ Lawlor notes that "Manson quotes a number of people who reject the asymmetry, but I will focus on the Harris quote in particular" (p. 354) Lawlor does not note that some of these quotations do not mention competence at all.
} 
competence and its asymmetry. ${ }^{9}$ Thus: 'Our way of framing the asymmetry loosens the connection to competence: neither paternalism, nor the asymmetry of consent and refusal, need be directly bound up with considerations of competence' (TP, p.73). The substantive part of the paper deals with the transitional paternalist explanation of the asymmetry and not one grounded in a theory of asymmetric of competence. The explicit point of the paper was to get away from a competence-based explanation. As such, my views (or Harris's) on the symmetry of competence, or otherwise, are orthogonal to the plausibility and defensibility of the account that is actually offered in 'Transitional Paternalism'.

\section{Misreading 2: transitional paternalism does not apply to particular decisions}

Lawlor argues that 'Transitional Paternalism' fails to recognise that the asymmetry of consent and refusal is to do with particular acts. He suggests that 'Transitional Paternalism' is focused upon types of acts, but as our puzzlement arises with regard to an asymmetry of consent or refusal to particular acts the account is inadequate.

Although it is true that the theory makes appeal to the normative powers that people have, and such powers are general (in the sense that they are powers to consent to, or refuse, any of broad range of interventions) the theory is clearly addressing, from the start, particular instances where an adolescent refuses, but some other party (parents, courts) permits a particular clinical intervention. Consider the quotation that Lawlor uses as part of his objection: 'the adolescent has the power to authorise a transaction of any value, but above a certain threshold the mother also has the power to do so. So, if the adolescent refuses to

\footnotetext{
${ }^{9}$ As I put it at the end of the section discussing the risk-related (asymmetric) standard of competence: ' there is no need to spend more time addressing the risk-related standard, for there is an alternative, more defensible, way to explain and justify our asymmetry. It is this more plausible explanation that will occupy us for the remainder of the paper.' (TP, p.69)
} 
authorise a payment at that level, the mother has the power to do so, even against the child's wishes' (p. 354; citing TP, p.71).

Here the point being made (as Lawlor recognises) is that if the child does not authorise $a$ (particular) payment (note it says "a payment" not "a type of payment") the mother can still authorise it (i.e., that particular payment, not some other payment that the mother has the power to authorise, and certainly not some other type of payment). ${ }^{10}$ This kind of "overriding" of the adolescent's refusal clearly must pertain to a particular refusal. So, when Lawlor says 'Manson is focused on a plurality of decisions' (p.354), that may be true, and for good reason: the account is one that makes appeal to the sharing of normative powers which do range over types of decisions. But it does not follow that such a focus precludes or excludes any application to the particular cases that those powers range over. The asymmetries that were under discussion (whether that of adolescent consent, or other types of case drawn upon by way of analogy ) arise with regard to consent (or refusal) in particular cases.

\section{The "sham offer" objection}

In 'Transitional Paternalism' the shared bank account analogy is meant to show that there is nothing fundamentally incoherent about an asymmetry of consent and refusal, and that such an asymmetry need not be grounded in considerations of competence. Lawlor, however, argues that the shared bank account example exhibits an incoherence, and, as such, it serves to underscore the incoherence of the asymmetry of consent and refusal,

\footnotetext{
${ }^{10}$ Note that "power to do so" in the sentence refers back, anaphorically, to the particular payment that the adolescent did not authorise (this is, of course an instance of a type of payment or an instance of a type of decision to pay). Lawlor seems to think that talk of types means one cannot talk of, or focus on, instances of that type.
} 
rather than lend plausibility to it. He asks us to consider a simple example where Mrs Jones shares a bank account with her adolescent daughter Lisa:

Imagine that Mrs Jones intends to pay Lisa's rent whether Lisa intends to or not. However, she doesn't want her daughter to think she is interfering, so she tells her, 'I'll leave it up to you. You can choose whether or not to pay your rent.' (Of course, even as Mrs Jones says this, she knows perfectly well that if Lisa decides not to pay, she will authorise the transaction herself.) Does Lisa have the choice to consent, but not to refuse, to pay the rent?

Lawlor then suggests that 'Lisa does not have a choice' As he puts it: 'If you have only two choices: $x$ or not-x, and if not-x isn't an option after all, then you have no choice: you get $x$, whether you like it or not' (p. 354).

The first point to note here is that this "sham choice" objection is disanalogous to the case of adolescent consent to treatment. Lawlor has one joint account holder making a sham offer-of the opportunity to pay the rent-to the other joint account holder. The mother says to Lisa: 'I'll leave it up to you. You can choose whether or not to pay your rent.' In the adolescent clinical context it is not the parent who is offering the choice to the child, it is the clinician. In the adolescent case, the analogy would be that the courts (as the party that shares the power to authorise treatment) were to ask the adolescent if she wanted to consent to treatment. However, the precise form of Lawlor's objection is not so important as the underlying intuition that it rests upon. Let us now clarify and strengthen this line of objection.

Mrs Jones, in Lawlor's example is making what we can call a sham offer of a choice. She is seeming to be offering to let Lisa choose, but, in fact, is doing no such thing. In a similar way, if I offer you a "choice" of tea or coffee, knowing full well that I have no coffee, and 
believing that whether you "choose" tea or coffee you will get tea, this is a sham offer. It would be no defence to say that it involved some kind of bizarre "asymmetry of choice", where your choice one way is respected, but the other way it is not. ${ }^{11}$ Why is such an offer "sham"? An offer is a species of speech act aimed at procuring an indication of choice on the part of the recipient with regard to the specified outcome. More accurately, it is aimed as procuring an indication of choice with regard to the speaker's acting in a way that will aim at securing the outcome. ${ }^{12}$ After all, to offer a choice is not to guarantee the outcome. Suppose A makes the offer of coffee believing that she has some, but then finds out that someone has stolen the coffee. If B replies positively she will not get what was offered, but the offer itself was a genuine one. An offer that is not fulfilled in the end is still an offer. A genuine offer does require a commitment on A's part to be appropriately responsive to B's choice (with regard to the specified offer) such that she will act accordingly.

First, $A$ must believe that she is able to act in a way aimed at fulfilling the offer. If $A$ and $B$ are in the woods far from any store and A offers $B$ a coffee knowing that $A$ has no access to coffee, it is a sham offer. ${ }^{13}$ But the speaker must do more than merely believe that she is able to fulfil the offer she has to be committed to doing so if the recipient chooses. Suppose A knows that she has plenty of coffee but also knows that she is selfish and doesn't want to share it. She wants to appear to be polite and generous and so makes an insincere offer of

\footnotetext{
${ }^{11}$ The term "asymmetry of choice" is Lawlor's terminology: 'if we say that there is an asymmetry of choice, between consent and refusal, we are suggesting that it makes sense to say that an individual has a choice, when we offer them the option to consent or to refuse, even if we know that we will not permit them to refuse treatment' (p. 355). This is what we will refer to below as a "sham offer".

${ }^{12}$ We will simplify matters considerably here, as our aim is not to engage in debates in philosophy of language or to give a complete survey of kinds of offers (e.g., offers can be made by one party such that another party will fulfil them: boss A offers guest B "Would you like coffee, if so my dependable minion C will make it for you").

${ }^{13}$ Indeed, it is arguable that an offer is "sham" even if by chance the offer can be fulfilled. If I have good reason to believe I have no coffee, offer you a coffee, but unbeknownst to me someone has placed a gift of coffee in the cupboard, the offer is still sham even though it can be fulfilled. What matters here is the intention with which the offer is made, and the beliefs that underpin that intention.
} 
coffee to B. If B accepts the offer A will lie-"Sorry, I forgot, I don't have any". This too is a sham offer. A could act in a way aimed at fulfilling it, but does not intend to do so. ${ }^{14}$ It should be stressed that an offer is not a promise. A does not-by her offer-put herself under an obligation to B to do X (and B may have no right to demand that A fulfil the offer). However, in making an offer the speaker intends to be responsive to the (expressed) choice made in response to the offer and, arguably, intends that the recipient recognise that she intends to be responsive in this way. The commitment to responsiveness also extends to the recipient's failure to respond, and to her declining the offer. ${ }^{15}$ If $A$ offers $B$ coffee with an intention to force coffee on B anyway, this would be to fail to make a genuine offer. ${ }^{16}$

The point that matters to us here is that a genuine offer seems to require a symmetry of responsiveness: A cannot properly be offering a choice of $X$ (or not) to $B$ if $A$ will only act appropriately in accord with one decision outcome, but not to the other outcome. The symmetry is that of having appropriate respect for acceptance or refusal either way. It thus seems that genuine offers involve a symmetry of responsiveness: the offer maker must be committed to responding appropriately (and differently) to the decision made by the respondent, whether positive or negative. But in the examples of adolescent treatment discussed in 'Transitional Paternalism' there is no symmetry of responsiveness. In seeking the adolescent's consent to treatment it seems that the clinician will be responsive to her choices (this would be the case if she were a competent adult). But, in fact, the clinician does not have a commitment to be responsive in a symmetrical way. If the patient accepts

\footnotetext{
${ }^{14}$ Offers can, of course, be offers to refrain ("Do you want me to stop whistling?") where fulfilling the offer requires the offer-maker to act in a way aimed at ceasing to do something.

${ }^{15}$ It also applies to A's belief. If $A$ believes that $X$ will happen whatever she does, she cannot genuinely offer $B$ the choice of $\mathrm{X}$ or not.

${ }^{16}$ These two necessary conditions for an offer being genuine admit of degrees. Indeed, there are at least three measures by which an offer can be more or less "sham". First the offer maker may have more or less evidence that the offer can be fulfilled. Second, she may have more or less confidence in that evidence (in light of, say, other beliefs that she has). Third, she can have more or less commitment to fulfilling the offer.
} 
the offer, and consents, she is treated, but if she refuses, rather than that being the last word on the matter, some other party may authorise the treatment, and it may be done in spite of her refusal.

The objection at this point-clarified and strengthened-is not yet conclusive. The objection is simply that the asymmetry of consent and refusal involves the making of sham offers. But is there anything wrong with the making of sham offers? Why shouldn't the clinician make sham offers if that is in the adolescent's best interests? Lawlor suggests that such offers would require deception on the part of the clinician: 'the approach he is endorsing relies on deception, letting adolescents believe they have a choice when, in reality, they do not' (p. 355). But couldn't the "asymmetric" offers be made nondeceptively? That is, suppose the clinician makes explicit the fact that she is not committed to being symmetrically responsive to the adolescent patient's choices. The adolescent now knows that a refusal might not be respected. But an explicit sham offer seems to be a pragmatically self-defeating speech act. Compare other pragmatically self-defeating speech acts like "Can you tell me the time, by the way, I don't want to know" or "Climate change is real, but I don't believe it". In making an explicit sham offer A both leads B to believe that she will be appropriately responsive to $B$, but then explicitly tells $B$ that she will not do so. It is unclear what role the making of the offer would play, given that the clinician is, in effect, saying "I am making you an offer to be treated or not, but it is not really an offer, because, either way you will be treated".

Sham offers require a distinctive kind of deception. This is because a sham offer involves the performance of an act of speech that is aimed at being taken to be a commitment to be 
responsive, whilst lacking such a commitment. The sham offer maker intends that the recipient falsely believe that she is committed to being appropriately responsive. Insofar as the asymmetry of adolescent consent and refusal involves the making of sham offers and such offers are deceptive, we have a problem. It would be very hard to justify practices of explicit deception of this kind within current clinical ethics (and rightly so).

\section{Genuine offers can be asymmetric}

Matters may now look very bad for 'Transitional Paternalism'. Indeed, they may look even worse than Lawlor's short objection suggests. A genuine offer of treatment would require a commitment to be symmetrically responsive to the recipient's choices. But we need to take care here. All of our examples of offers so far have been ones where an offer is made to an individual respondent. If $\mathrm{A}$ makes an offer to $\mathrm{B}$ do $\mathrm{X}$ then $\mathrm{A}$ must have a commitment to be responsive to $B^{\prime}$ s choice. In our examples so far there has been no third party $C$ who has a "say" in the choice. But not all (genuine) offers are directed at a sole individual. For example, suppose A makes a simple disjunctive offer to both B and C "Do either of you want this bottle of olive oil?" Insofar as the offer is genuine A must still have a commitment to be appropriately responsive, but what constitutes "appropriate responsiveness" is not the same as it would be if the offer were made to one party alone. If either B or C answers "yes" then A ought to give that party the bottle. If neither responds positively, then A ought not to force the bottle upon either of them. The offer might be even more complex in the limitations it puts upon the significance of either recipient's choices. Suppose A adds the condition "First one to reply gets it". Suppose B replies (positively) before C (also positively). Now suppose we were to focus upon $A$ and $C$ alone. Suppose we leave out the particular 
social context of the offer, and certain features of the offer. With that kind of selective focus it might seem that we have a "sham" offer here. A knew up front that if $\mathrm{C}$ responded positively (after B had got in first), C's choice would not be respected. ${ }^{17}$ But this is not a sham offer. A's offer is responsive and appropriately so, but what counts as appropriate is shaped by the context within which the offer is made. In this context (but not others) the choices of more than one party are in play and their significance depends upon their relative position. This kind of situation involves a responsiveness that is not symmetrical in a simple way for the choices of each party individually. On the "refusal" side, for both respondents, if they say "no" they will not get the bottle. But if either says "yes" it is does not follow that A will act in a way aimed at giving them the bottle. A may, or may not, do so depending on what the other party has chosen and (here) when they communicated their choice to A. In complex social contexts offers need not exhibit a symmetrical responsiveness to any individual within that context.

Let us return to the the joint bank account example. Suppose the bank offers Lisa the choice to authorise a particular payment: "We have a demand for payment, do you want to authorise it?". However, if Lisa does not pay, then the bank will then ask Mrs Jones if she wants to. This is not a sham offer. The bank is committed to being responsive to Lisa's choices. The key point is that the bank need not be committed to being responsive in the exact same way that it would be if Lisa were the sole account holder. Unlike the offer of choice to a sole-account holder if Lisa says "yes" the payment will be authorised, if Lisa declines, then given the nature of the joint account the bank need not take that as the "last

\footnotetext{
${ }^{17}$ Another simple example is that of (certain kinds of) conjunctive offer. For example, A offers both $B$ and $C$ the opportunity to play tennis together on her court. If only one of them affirms the offer is not fulfilled. The practical significance of each of $B$ and $C^{\prime}$ 's choice is dependent upon what the other chooses. The dependency here is not the same as that found in the disjunctive example above.
} 
word". The bank can then ask Mrs Jones if she will authorise the payment. If both of them decline, the bank ought not to authorise the payment; if either accept, then it ought to do so. There is nothing sham about an offer being made in a context that is not exactly the same as a binary offer to single individual where only one party's choices are of significance.

Here we can avail ourselves of a simple test for genuine, as opposed to "sham" offers by asking whether it would be pragmatically self-defeating if the bank explicitly asks: "Will you pay $\mathrm{X}$, but bear in mind that if you don't we will ask the other account holder?" If Lisa is aware that she is a joint account holder with her mother, there is nothing self-defeating or odd about such an offer. The bank is committed to being appropriately responsive to choices, but what it is to be appropriately responsive is tailored to the context in question. Because the bank account is shared, more than one party's choices are of significance.

The underlying error here is to assume that there is only one way that a genuine offer can be responsive: a simple, symmetrical, responsiveness where "Yes" leads to $\mathrm{X}$ being done, "no" does not. This line of thought makes it seem as if there is something "built in" to an offer's being genuine that it be symmetrically responsive to both positive and negative responses. But, as we noted above, offers-genuine offers-can be made in all sorts of complex social contexts were the offer-maker is responsive to the choices made, but in accordance with the particular "set up" within which the offer is made. Genuine offers can be asymmetric.

\section{Must an offer of treatment be symmetrically responsive?}


Suppose we accept that, in general, genuine offers need not exhibit the symmetry of responsiveness to any individual's choices, especially if offers are made within complex social contexts where more than one party has a "say". We might still have the intuition that where clinical treatment is concerned the responsiveness in question must be symmetrical. In many everyday contexts there is scope for leeway or "slack" in the offermaker's responsiveness and this slack can underpin an asymmetry. For example, suppose $\mathrm{A}$ offers $B$ coffee and $B$ declines. But $A$ knows $B$ well. and $A$ knows that that $B$, although a coffee lover, is prone to being overly polite and does not like being a burden on others. A then judges: "Oh, she's probably being polite, I will make her one anyway". Suppose $A$ is correct in her assessment. B might be grateful-"Oh, thanks! I was dying for a coffee. I only said "No" because I didn't want to trouble you!". Had B said "Yes" she would have got coffee. But saying "no" gets her coffee too, because of the additional information available to $A$ that allows her to interpret the significance of B's choice.

Here the explanation of the asymmetry is that in many everyday contexts, where offers are made, the choices made by the recipient may be acknowledged, but weighed up in the balance alongside other considerations. B's response provides A with information that A can then take into account in deciding whether or not to act in the way specified. ${ }^{18}$ Where this is so, then there is scope for an asymmetry between consent and refusal. A refusal might be taken into account, but outweighed by other considerations, so that the response made is the same as it would be if a positive reply had been given.

\footnotetext{
18 These points build upon Suzanne Uniacke's useful contrast between "consideration respect" and "compliance respect" see S. Uniacke. 2013. Respect for autonomy in medical ethics. in Reading Onora O'Neill. D. Archard et al. Routledge: 94-110. They also build upon the brief discussion of the contrast in TP, p. 72.
} 
But this cannot help us in defending the asymmetry of adolescent consent and refusal. Such leeway in responsiveness is not morally or legally justifiable in the context of clinical treatment. This is because the patient has moral and legal rights against (many) clinical actions being performed without her consent. Unlike the "coffee" example just above if B declines the offer of treatment, clinician $A$ has strong normative reasons to refrain from treating B. A would wrong B by trying to treat in the face of refusal (and may breach legal rights that B has). Unlike our "coffee" example, it is no defence for A to say "I thought B was just being polite so I ignored her refusal". In short, B's rights provide a very strong reason for ensuring responsiveness to B's refusal.

A similar point applies to the clinician's responsiveness to acceptance of the offer. Although $B$ has rights against acts that impinge upon her body she also has the normative power to create exceptions to those rights by her act of consent. By itself consenting to something does not entail that it will be done. If B places a sign by her vineyard saying "Free grapes" she consents to grapes being taken but it may be that nobody ever takes a grape. But consent in a clinical context is not like this. The relationship between clinician and patient generates obligations upon the clinician to act in her patient's best medical interests. The patient's rights act as "barrier", but a barrier that the patient can remove by her consent. The patient knows that if she consents, then clinician will be disposed to perform the specified acts (though consent can be revoked prior to treatment). It would be very odd for a clinician who has proposed treatment to say "Thanks for permitting me to treat you in the way I suggested, but I will not do so". Given the background obligations upon the clinician, the patient's response thus has a strong practical significance for the clinician. 
Lacking the option for "leeway" found in many everyday offers and responses, there is thus good reason why clinical treatment involves a symmetry of responsiveness. Refusals should be respected because of the rights that the patient has. Consent should be respected because of the power the patient has, and the obligations that the clinician has. In this kind of context it would be a "sham" offer to propose treatment whilst holding that the treatment will be performed in spite of a refusal (it would also involve deceptive concealment).

But offers can be made in a wide variety of contexts and although all genuine offers involve a commitment to responsiveness of some kind, the responsiveness need not be symmetrical with regard to the specific choices made by this or that particular respondent. In our "first to reply gets the bottle" example, C's saying "no" will lead to her not getting the bottle, but her saying "yes" may or may not. This "first to reply" example is not meant to provide an analogy with adolescent consent-they are clearly different-it is simply meant to show that offers and choices can be genuine without a symmetry of responsiveness. If the argument in 'Transitional Paternalism' is correct there are good-albeit paternalisticreasons why, in some cases, the normative power to permit treatment should be shared. Where normative powers are shared choices offers need not behave in the same way that they do when powers to permit are not shared. In the case of adolescent consent for, say, life-saving treatment, not only is the normative power to authorise treatment shared (as in our bank account example), there is also a specific ordering of powers and conditions upon the exercise of such powers. It is not the case that the adolescent and the court are both asked, at the same time, whether they permit the treatment (e.g., "first to reply gets to authorise"). Nor is the court asked first. The court's power only becomes "active" as it were 
if the adolescent has refused. Note also that it is not the case that if the adolescent refuses the court thereby exercises it power. The adolescent's refusal only activates the power, refusal does not fix the court's decision about how to exercise that power. The court may, all things considered, decide not to authorise treatment.

So, here we have a highly complex, structured, social decision-making context where different parties have the power to permit treatment, but only once certain conditions or provisos are met. In such a context, the significance of the adolescent's choice is dependent upon a number of things in a way that an adult's choices are not. The normative significance of her choice (and, in light of this, the practical implications of her choice) depend upon: (i) the type of treatment being offered (for routine, low-risk interventions, the situation is a symmetrical one); (ii) whether she accepts or declines that offer (if she accepts and consents, the court has no veto power, for example); (ii) if she declines, what is done depends upon what some other party-the shared power holder-then decides. This is very unlike the simple situation for adult consent with only one party having the "final word" on permissibility of treatment. As such, it is no surprise that the clinician's responsiveness to the adolescent's choices need not be as it would have to be in the adult case. When the clinician offers treatment, if neither the adolescent nor the courts permit it, then that "total" response ought to be respected: the clinician refrains-or, at least, ought to refrain-from treatment. If the adolescent permits treatment, then her positive response is respected: treatment is given. If the adolescent refuses, then the court is consulted. If, after deliberation, the court chooses to exercise its power to authorise the treatment then that choice is respected: treatment is given (leaving aside for now issues about how such treatment might actually be performed against the patient's wishes). This is responsiveness, 
and a responsiveness that is appropriate to the situation, but it is not the symmetric responsiveness we find in binary offers to single respondents, or that we find in adult consent to treatment where powers to permit are not shared.

Our discussions show two things. First, that genuine offers can be asymmetrically responsive to individual choices. Second, there can be different reasons for being asymmetrically responsive. The reason why there is an asymmetry of response in the "first to reply gets the bottle" example is not the same as the explanation of the asymmetry in the "politeness" case, where a refusal is weighed up against other information and overruled. It is thus no objection to say that in clinical treatment there is no leeway for responsiveness, not all asymmetric cases are grounded in this kind of leeway.

We have clarified and strengthened what seems to be a powerful and intuitive objection to the asymmetry of adolescent consent and refusal. But such an objection fails. It seems plausible, but only if we assume that all genuine offers must involve a simple symmetry of responsiveness, where the offer of $X$ or not is met by doing $X$ if B says "yes" and met by not doing $X$ is B says "no". We are apt to be misled here because adult consent to clinical treatment is a context where there are strong reasons why there should be a symmetrical responsiveness to the patient's choices. But it is simply a mistake to then argue that therefore the offer of treatment to adolescents must involve the same symmetry of responsiveness. To do so is simply to beg the question against the position in 'Transitional Paternalism'. If the arguments in 'Transitional Paternalism' are right there are good reasons why the context of adolescent consent to treatment is one that ought not to exhibit the symmetry of responsiveness found in adult consent to treatment. One reason why it does 
not do so is that normative powers are shared (in the ranked, conditional, way noted above) in the adolescent case but not the adult case. It may be, of course, that we think that adolescents should not share the power to permit their own treatment with others-and this would afford them a greater degree of indirect control over their treatment - but that is not the same as the direct "sham choice" or "sham offer" objection.

\section{A final error: confusing the normative significance of consent with the normative status} of acts of consent

We have now clarified and responded to the a challenging objection against the asymmetry of adolescent consent and refusal. Lawlor has a final objection that can be responded to more briefly. Having argued that the asymmetry involves sham offers (what Lawlor calls an "asymmetry of choice") Lawlor asks whether the asymmetry of consent and refusal might be defensible if we view it in a different way:

Manson could claim - legitimately - that he was defending the asymmetry of permissibility, not the asymmetry of choice. The claim, therefore, is that we should give adolescents the right to consent, but not to refuse. On this interpretation, Manson is talking about what the law should permit, and what it should not. He is arguing that adolescents should be permitted to consent to treatment, but should not be permitted to refuse treatment. (p. 355)

It is very odd to claim that I was arguing that adolescents "should not be permitted to refuse treatment". Indeed, the theory developed in 'Transitional Paternalism' cannot be committed to the claim that adolescents are not permitted to refuse treatment. As we saw above, the theory holds that the discretionary power of the courts only becomes "active" 
after the adolescent has refused. If adolescents are not permitted to refuse treatment, then the court's power could never be deployed (unless they acted impermissibly).

It is worth briefly expanding on the mistake here. If we are to be clear about the asymmetry of adolescent consent and refusal we need to keep apart the normative significance of an act of consent (or refusal) with the normative status of that act of consent (or refusal). The former concerns the normative changes that the adolescent brings about (or fails to bring about) by her acts, the latter concerns the permissibility or otherwise of acting in such a way. These are not the same thing. To talk about the permissibility of refusal is to talk of the normative status of such an act, not about its normative implications or significance. In our joint bank account example, each account holder is entitled to refuse to pay (that is, the normative status of refusal is: permissible); but given the arrangement of normative powers, in some cases, a refusal will not have the kind of normative significance it would have in the sole account case (i.e., the payment is made anyway).

There is a reason why it is easy to be confused here. The power to permit or authorise one's own clinical treatment is a discretionary one: the patient is under no obligation to consent and under no obligation not to consent. Her consent is thus both permissible and omissible and so too is her refusal. Suppose we now try to try to articulate the contrast between the asymmetric adolescent consent and symmetric adult consent. The thing that might strike us is that the adolescent's power is restricted relative to the adult's power. Unlike the adult, she cannot conclusively block the authorisation of her treatment. At this point it may seem natural to view such limits to the adolescent's power as a restriction on the adolescent's discretion to exercise her power. That is, we conclude that the restriction on her power is because she is not permitted to refuse. But this is not the right way to draw 
the contrast at all. The adolescent is permitted to refuse-and, as we saw, the court's power is only "activated" once she has refused-but their refusal does not have the same normative significance as an adult refusal. That is once they have refused, some other party has the power to authorise treatment.

\section{Conclusion}

We have viewed a number of arguments against 'Transitional Paternalism', and against the asymmetry of adolescent consent and refusal, none of them succeed. First, 'Transitional Paternalism' was not only concerned with types of decisions rather than specific decisions, and the original text made this clear. Second, the original paper was not an argument against Harris in favour of asymmetric competence. The (avowed) aim was to offer an explanatory (and justificatory) framework for the asymmetry that goes beyond a focus on competence (symmetric or otherwise).

The third objection was the most challenging one. But the "sham offer" (or "asymmetry of choice") objection fails too. Whilst many kinds of offer making, in many contexts, require a commitment to a symmetry of responsiveness this is not the case for all offers in all contexts. If 'Transitional Paternalism' is correct, adolescent consent is a context that does not require a symmetry of responsiveness to the individual adolescent choice's. It is thus not a valid objection to the theory to say that the offer of treatment does not involve the kind of symmetrical responsiveness that we find in adult consent. It simply begs the question against the theory to say that the adolescent's choices do not have the significance 
that they would were she an adult with the sole unshared power to permit her own treatment.

Finally, the suggestion that the theory is really about the "asymmetry of permissibility" conflates the normative status of refusal with the normative significance of that refusal. Indeed, the account developed in 'Transitional Paternalism' is one framed in terms of the courts' powers coming into play only after the adolescent has refused so the theory must make space for refusals being permissible.

In responding to these misunderstandings it is hoped that we have gained a better view of exactly what is going on in the asymmetry of adolescent consent and refusal. It is also hoped that this clarification is of some use, as-it would seem-this is an topic that is ripe for misinterpretation and confusion. Such a clarification, of course, does nothing to justify the sharing of normative powers which generates the asymmetry of consent and refusal, but the objections discussed here do not engage in any direct way with those broader-and challenging-questions about the asymmetry of adolescent consent and refusal and its legitimacy. ${ }^{19}$

\footnotetext{
${ }^{19}$ E.g., see Faye Tucker 'Developing Autonomy and Transitional Paternalism', Bioethics (forthcoming) for some careful critique of, and development of, the Transitional Paternalist account.
} 